\title{
Heart disease in a mutant mouse model of spontaneous eosinophilic myocarditis maps to three loci
}

\author{
Nives Zimmermann ${ }^{1,2}$, William J. Gibbons Jr ${ }^{3}$ Shelli M. Homan ${ }^{3}$ and Daniel R. Prows ${ }^{2,3^{*}}$ (D
}

\begin{abstract}
Background: Heart disease (HD) is the major cause of morbidity and mortality in patients with hypereosinophilic diseases. Due to a lack of adequate animal models, our understanding of the pathophysiology of eosinophilmediated diseases with heart complications is limited. We have discovered a mouse mutant, now maintained on an A/J inbred background, that spontaneously develops hypereosinophilia in multiple organs. Cellular infiltration into the heart causes an eosinophilic myocarditis, with affected mice of the mutant line (i.e., $A / J^{H D}$ ) demonstrating extensive myocardial damage and remodeling that leads to HD and premature death, usually by 15-weeks old.

Results: Maintaining the $\mathrm{A} / \mathrm{J}^{\mathrm{HD}}$ line for many generations established that the HD trait was heritable and implied the mode of inheritance was not too complex. Backcross and intercross populations generated from mating $A / J^{H D}$ males with females from four different inbred strains produced recombinant populations with highly variable rates of affected offspring, ranging from none in C57BL/6 J intercrosses, to a few mice with HD using 129S1/SvIm J intercrosses and C57BL/6 J backcrosses, but nearly $8 \%$ of intercrosses and $>17 \%$ of backcrosses from SJL/J related populations developed HD. Linkage analyses of these SJL/J derived recombinants identified three highly significant loci: a recessive locus mapping to distal chromosome 5 ( $L O D=4.88$; named Emhd1 for eosinophilic myocarditis to heart disease-1); and two dominant variants mapping to chromosome 17, one (Emhd2; LOD $=7.51$ ) proximal to the major histocompatibility complex, and a second (Emhd3; $L O D=6.89$ ) that includes the major histocompatibility region. Haplotype analysis identified the specific crossovers that defined the Emhd1 (2.65 Mb), Emhd2 (8.46 Mb) and Emhd3 (14.59 Mb) intervals.

Conclusions: These results indicate the HD trait in this mutant mouse model of eosinophilic myocarditis is oligogenic with variable penetrance, due to multiple segregating variants and possibly additional genetic or nongenetic factors. The $\mathrm{A} / \mathrm{J}^{\mathrm{HD}}$ mouse model represents a unique and valuable resource to understand the interplay of causal factors that underlie the pathology of this newly discovered eosinophil-associated disease with cardiac complications.
\end{abstract}

Keywords: Churg-Strauss Syndrome, Dilated cardiomyopathy, Disease model, Eosinophil-associated disease, Heart failure, Hypereosinophilia, Linkage mapping, Oligogenic trait, QTL, Spontaneous mouse mutant

\footnotetext{
* Correspondence: daniel.prows@cchmc.org

2Department of Pediatrics, University of Cincinnati College of Medicine,

Cincinnati, OH, USA

${ }^{3}$ Division of Human Genetics, Cincinnati Children's Hospital Medical Center,

3333 Burnet Avenue, Bldg. R. MLC 7016, Cincinnati, OH 45229-3039, USA

Full list of author information is available at the end of the article
}

(c) The Author(s). 2019 Open Access This article is distributed under the terms of the Creative Commons Attribution 4.0 International License (http://creativecommons.org/licenses/by/4.0/), which permits unrestricted use, distribution, and reproduction in any medium, provided you give appropriate credit to the original author(s) and the source, provide a link to the Creative Commons license, and indicate if changes were made. The Creative Commons Public Domain Dedication waiver (http://creativecommons.org/publicdomain/zero/1.0/) applies to the data made available in this article, unless otherwise stated. 


\section{Background}

Discovering a spontaneous mouse mutant and the genetic variants underpinning its disease can be invaluable in the pursuit of understanding the corresponding human disease. Once identified, these mutants can provide the means to investigate the disease, understand the associated pathological mechanisms and discover new therapies. Usually, natural mutants involve a single de novo gene mutation that often can be identified quickly with current mapping and next generation sequencing technologies. However, the causal variants for about half of spontaneous mutants have evaded discovery by exome sequencing [1]. Many reasons can explain why mutations go undetected using exome sequencing, including poor gene annotations, poor exon capture, intronic mutations or variants in upstream or downstream regulatory regions, structural and copy number variants, epigenetic changes, and environmental effectors. In addition, it is likely that many unmapped mutant traits result from decreased penetrance due to multiple segregating genetic variants. One explanation for the sudden discovery of a complex trait is that one or more contributing variants lie dormant and do not cause disease on their own. But, when the effects from a critical new mutation combines with the prior latent variant(s), the mutant trait is revealed. In this setting, such an oligogenic trait would appear to be Mendelian.

In this report, we describe the genetic mapping of a complex trait discovered in our mouse colony. From the founder spontaneous mutant, we have established a novel mouse line on a SNP-verified A/J inbred background. Affected mice of this line naturally (i.e., uninduced) develop an eosinophilic myocarditis (EM) that progresses to heart disease (HD) and death, with almost three-quarters of affected mice dying by 15 -weeks old [2]. Penetrance of the disease trait is reduced and varies greatly among the breeder pairs, consistent with multiple genetic variants still segregating for the EM/HD trait. However, we have maintained this mutant line as an $\mathrm{A} / \mathrm{J}$ inbred strain (designated as $\mathrm{A} / \mathrm{J}^{\mathrm{HD}}$ ) for over twenty generations without a reliable screening marker, suggesting that heritability of the trait is not exceedingly complex. Litter ratios of affected-to-unaffected offspring show a large and breeder-pair specific range, indicating that causal variants are still segregating in the population and among the breeders. However, extensive pedigree data for hundreds of matings over many generations implicates 2-3 genes (depending on their modes of inheritance) segregating in the $\mathrm{A} / \mathrm{J}^{\mathrm{HD}}$ mutant line, indicating to us that mapping the EM/HD trait should be feasible.

Using quantitative trait locus (QTL) analysis, we have discovered three highly significant loci, designated Emhd1-3 for 'Eosinophilic myocarditis to heart disease'. These three QTLs include a homozygous recessive variant residing on distal chromosome 5 (Emhd1) and two distinct QTLs on chromosome 17; one (Emhd2) that maps proximal to the major histocompatibility complex $(\mathrm{MHC})$ and a second interval (Emhd3) that includes the MHC. Evaluating the mice used for QTL mapping, haplotype analysis identified specific recombinations that delineated the proximal and distal ends of each QTL interval. Together, these three QTLs explain $\sim 64 \%$ of total trait variance, implicating the potential involvement of one or more other factors. The established $\mathrm{A} / \mathrm{J}^{\mathrm{HD}}$ line offers a powerful resource to identify the set of causal variants (coding and noncoding) underlying these three QTLs and any additional genetic or non-genetic factors that contribute to the increased susceptibility, or to the initiation or progression of disease. Knowing the genes involved in EM/HD will allow targeted studies to understand the pathologic mechanisms at play for this and possibly other eosinophil-related diseases with cardiac manifestations, for which little genetic information is currently recognized.

\section{Results}

\section{General heart pathology of $A / J^{\mathrm{HD}}$ mutant mice}

Whole-mount images of hearts from an $\mathrm{A} / \mathrm{J}^{\mathrm{HD}}$ litter are presented in Fig. 1. No indications of HD were observed in three siblings (Fig. 1a-c), whereas signs of HD were noted in three of their littermates, including one heart of approximately normal size with significant atrial and ventricular fibrosis (Fig. 1d) and two with extensive right ventricular dilatation and dramatic right outer wall thinning that approached transparency (Fig. 1e-f). To confirm the extensive fibrosis seen in the myocardium of affected mutants, hearts from mice with HD were stained with Trichrome. A representative affected mutant heart (Fig. 2b) with images taken at several sites (indicated by arrows) and increased magnifications (Fig. 2c-h) and compared to an unaffected $\mathrm{A} / \mathrm{J}^{\mathrm{HD}}$ littermate (Fig. 2a).

\section{Replicating the trait in recombinants}

We have sustained the mutant line for more than 20 generations as an A/J inbred strain (verified by MegaMuga SNP analysis). Although mutant mice are inbred, they differ from A/J mice for segregating variants involved in the trait. Because we do not yet know the responsible genes, we have preserved the necessary pool of disease-associated alleles by consistently maintaining about 10 mating pairs. Breeder pairs are selected to have at least one mate that had a parent or a sibling that died of $\mathrm{HD}$, such that mating pairs are parent-offspring, brother-sisters from the same litter, or brother-sisters from different litters of same parents. To map these causal variants, our goal was to reproduce the disease trait dozens of times in recombinant mice generated from at least two different strains. To detect both 

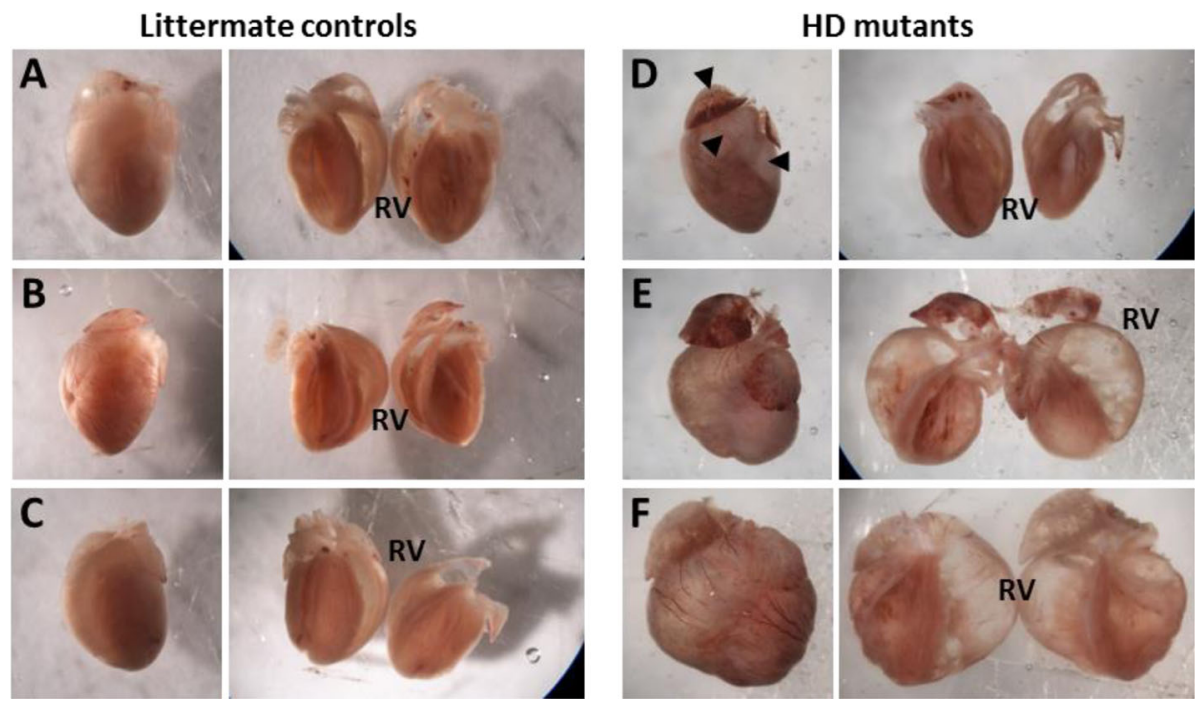

Fig. 1 Dissection microscope photos. Whole mounts with coronal cuts for hearts removed from littermate controls (a-c) and three mutants (d-f). All three mutants had visible signs of heart disease. Two mutants (e, f) show evidence of left atrial enlargement, right ventricular dilation with dramatic right wall thinning, and left ventricle hypertrophy. A third mutant (d) presents as slightly smaller than controls, but with significant atrial and ventricular fibrosis (arrow heads). All photos were taken at the same settings

dominant and recessive linkage, we first used an $\mathrm{F}_{2}$ breeding scheme. For all crosses, proven mutant males were used in the initial outcrosses $\left(F_{1}\right)$ for each strain. Then daughters were backcrossed with sires or intercrosses were performed to generate the recombinant populations. Initially, $\mathrm{F}_{1}$ hybrids produced from C57BL/6 J (B6) females and proven $\mathrm{A} / \mathrm{J}^{\mathrm{HD}}$ mutant males were intercrossed to generate a cohort of $102 \mathrm{~B} 6 . \mathrm{A} / \mathrm{J}^{\mathrm{HD}}$ (B6.HD) $\mathrm{F}_{2}$ mice (Additional file 1, see 1A); unexpectedly, none of these B6.HD$\mathrm{F}_{2}$ recombinants developed HD (Table 1). A second B6.HD- $\mathrm{F}_{2}$ population (Additional file 1, see $1 \mathrm{~B}$ ) was generated using different mutant male breeders, but also yielded no mice that developed HD $(n=181$; Table 1$)$. Compared to the 2-3 genes estimated to be segregating in the $\mathrm{A} / \mathrm{J}^{\mathrm{HD}}$ inbred line, these B6.HD- $\mathrm{F}_{2}$ data ( 0 affected in $283 \mathrm{~F}_{2}$ mice) suggested a considerably more complex pattern of trait inheritance (i.e., at least 5 variants or other genetic or non-genetic factors).

Our second attempt concurrently generated two distinct recombinant populations to further explore whether the HD trait could be recapitulated in a mapping cross (Additional file 1, see right). For these crosses, we changed the mating scheme for one recombinant population and switched the inbred strain for the second. The first population again used B6 females, but this time in a backcross strategy to potentially double our chances of recapitulating the trait (Additional file 1, see 2A). In this case, a small cohort of B6 backcrosses $\left(\mathrm{B} 6 . \mathrm{HD}-\mathrm{N}_{2}\right.$ ) was produced by using each mutant $\mathrm{A} / \mathrm{J}^{\mathrm{HD}}$ male (proven sires) for both the initial $F_{1}$ outcross and the subsequent backcrosses with his daughters; still, just one of $50(2 \%)$ B6.HD- $\mathrm{N}_{2}$ recombinants developed HD (Table 1). Concomitantly, we generated $266 \mathrm{~F}_{2}$ recombinants from mutant $\mathrm{A} / \mathrm{J}^{\mathrm{HD}}$ males and $129 \mathrm{~S} 1 / \mathrm{SvImJ}$ (S1) inbred females (Additional file 1, see 2B); two S1.HD- $\mathrm{F}_{2}$ mice developed HD $(0.75 \%$ affected $)$. Thus, although rare, HD was recapitulated in two different inbred strain-pairs and two breeding schemes, demonstrating that mapping the trait might be possible; however, this would require a huge population of recombinant mice to produce the number of affected mice required for linkage analysis. Still puzzling, however, was the discrepant rates of $\mathrm{HD}$ seen between these mapping crosses and the inbred $\mathrm{A} / \mathrm{J}^{\mathrm{HD}}$ line.

\section{Improving the rate of affected recombinant mice}

To explain the disparity between the estimated number of segregating causal mutations in the $\mathrm{A} / \mathrm{J}^{\mathrm{HD}}$ line compared to the recombinants from B6.HD- $\mathrm{N}_{2}, \mathrm{~B} 6 . \mathrm{HD}-\mathrm{F}_{2}$, and S1.HD- $\mathrm{F}_{2}$ crosses, we hypothesized that one or more causal variants contributing to EM/HD must already exist as fixed polymorphism(s) in the $\mathrm{A} / \mathrm{J}$ inbred strain (and the $\mathrm{A} / \mathrm{J}^{\mathrm{HD}}$ inbred mutant line). Because one or more of these $\mathrm{A} / \mathrm{J}$ polymorphisms are fixed as homozygous, they are masked when maintaining the $\mathrm{A} / \mathrm{J}^{\mathrm{HD}}$ line with brother-sister and parent-offspring matings. However, these fixed mutations begin to segregate when the $\mathrm{A} / \mathrm{J}^{\mathrm{HD}}$ line is outcrossed with another inbred strain for the mapping studies, which significantly reduces the odds to reestablish the full set of allelic variants needed to cause HD. Given the large difference in the rates of affected offspring between $\mathrm{A} / \mathrm{J}^{\mathrm{HD}}$ and its mapping 


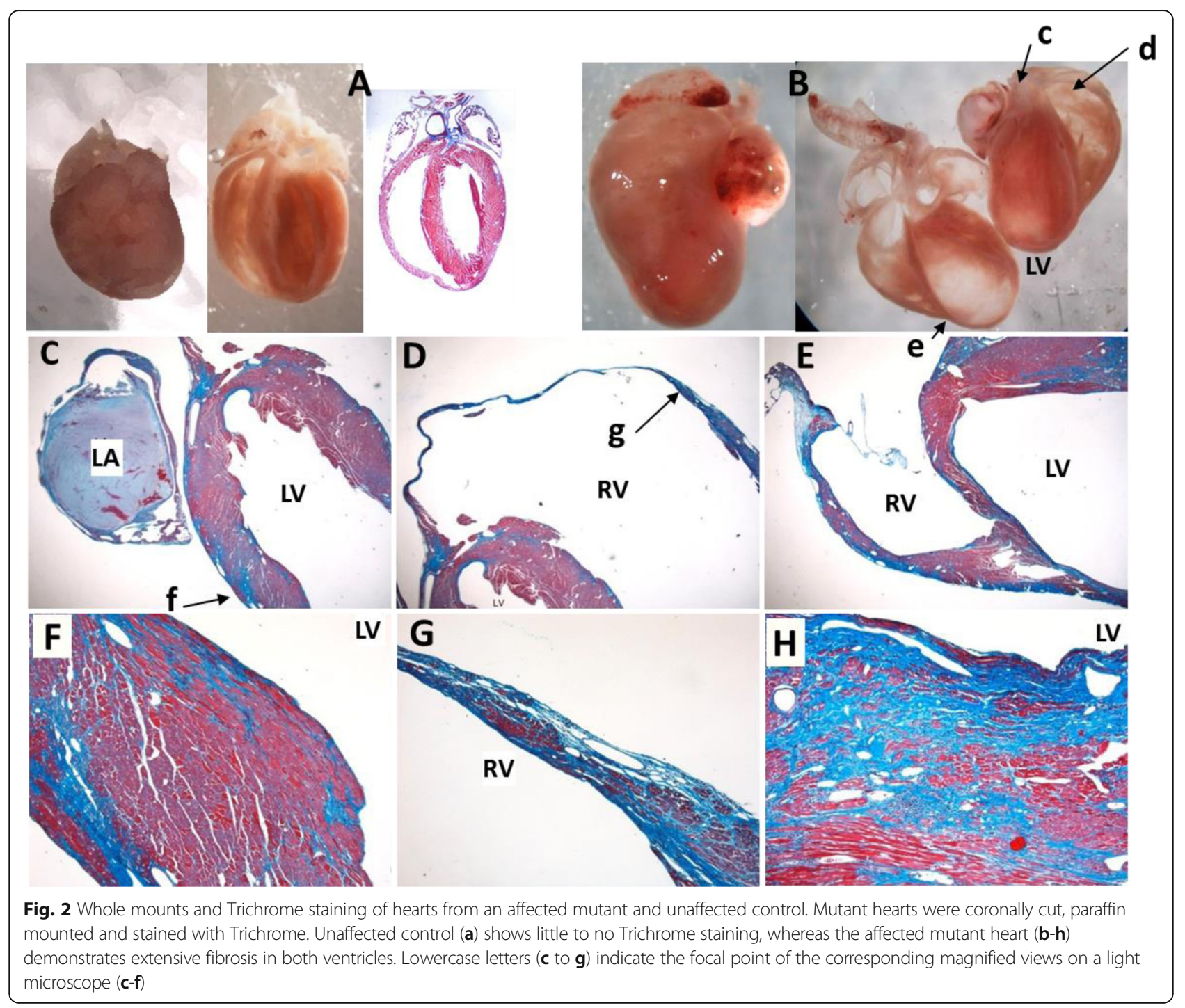

Table 1 Crosses used to produce mice for EM/HD mapping

\begin{tabular}{|c|c|c|c|c|c|}
\hline Recombinant Cross & \# litters & $\widehat{\delta}$, affected & Q, affected & total, affected & $\%$ affected \\
\hline$\overline{\left(B 6 \times A / J^{H D}\right) F_{2}}$ & $\begin{array}{l}10 \\
15\end{array}$ & $\begin{array}{l}54,0 \\
84,0\end{array}$ & $\begin{array}{l}48,0 \\
97,0\end{array}$ & $\begin{array}{l}102,0 \\
181,0\end{array}$ & $\begin{array}{l}0 \\
0\end{array}$ \\
\hline$\left(B 6 \times A / J^{H D}\right) N_{2}$ & 5 & 21,0 & 29,1 & 50,1 & 2.0 \\
\hline$\left(\mathrm{S} 1 \times \mathrm{A} / J^{H D}\right) \mathrm{F}_{2}$ & 32 & 123,0 & 143,2 & 266,2 & 0.75 \\
\hline $\begin{array}{l}\left(\mathrm{D} 2 \times \mathrm{A} / \mathrm{J}^{\mathrm{HD}}\right) \mathrm{F}_{2} \\
\text { (C5 deficient) }\end{array}$ & 58 & 262,9 & 248,6 & 510,15 & 2.9 \\
\hline $\begin{array}{l}\left(\mathrm{D} 2 \times \mathrm{A} / \mathrm{J}^{\mathrm{HD}}\right) \mathrm{N}_{2} \\
(\mathrm{C} 5 \text { deficient })\end{array}$ & 26 & 114,7 & 122,13 & 236,20 & 8.5 \\
\hline $\begin{array}{l}\left(\mathrm{SJ} \times \mathrm{A} / J^{\mathrm{HD}}\right) \mathrm{F}_{2} \\
\text { (Dysf deficient) }\end{array}$ & 31 & 148,12 & 139,10 & 287,22 & 7.7 \\
\hline $\begin{array}{l}\left(\mathrm{SJ} \times \mathrm{A} / J^{\mathrm{HD}}\right) \mathrm{N}_{2} \\
\text { (Dysf deficient) }\end{array}$ & 13 & 42,8 & 56,9 & 98,17 & 17.3 \\
\hline
\end{tabular}


crosses, it is plausible that more than one latent $\mathrm{A} / \mathrm{J}$ variant is affecting the HD trait. By choosing a strain with the same or functionally similar mutation as in A/J, we could indirectly test this possibility while still attempting to generate recombinants for mapping. Because of their potential role in EM/HD pathology, hemolytic complement (C5) and dysferlin (Dysf) were prioritized from the list of 14 known mutated disease genes in $\mathrm{A} / \mathrm{J}$ inbred mice (see: https://www.jax.org/strain/000646 View Genetics).

\section{C5}

Two conceivable mechanisms of disease initiation include 1) an unknown pathogen acts as a trigger or 2) an unknown self-protein induces an autoimmune response. C5 has a potential role in both: C5 deficiency increases susceptibility of $A / J$ mice to many infectious agents [3-6] and $\mathrm{C} 5$ function and dysfunction are indicated in immunity and autoimmunity $[7-11]$. From this, we predicted that the effects from the natural $C 5$ mutation in the A/J strain [12] combines with that of the de novo mutation (and possibly other latent mutations) in our $\mathrm{A} / \mathrm{J}^{\mathrm{HD}}$ line to cause disease. To test this hypothesis $\mathrm{A} / \mathrm{J}^{\mathrm{HD}}$ males were mated with DBA/2 J (D2) females, an inbred strain that carries the same 2-bp deletion in $C 5$ as does $\mathrm{A} / \mathrm{J}$ [13]. These matings necessarily produce litters in which all recombinant offspring have homozygous mutant copies of $C 5$ (as do the $\mathrm{A} / \mathrm{J}$ and $\mathrm{A} / \mathrm{J}^{\mathrm{HD}}$ lines). If $\mathrm{C} 5$ deficiency contributes to disease, then the odds are improved that the breeders will carry the required set of mutant alleles and produce more affected recombinant offspring.

D2 mice were bred using $F_{2}$ and $\mathrm{N}_{2}$ mating schemes (Additional file 1, bottom) to evaluate a potential role of C5 in EM/HD and to produce recombinants for mapping the causal variants of HD. Cohorts of 510 intercross mice $\left(\mathrm{D} 2 . \mathrm{HD}-\mathrm{F}_{2}\right)$ and 236 backcross mice (D2.HD- $\mathrm{N}_{2}$ ) for a total of $746 \mathrm{D} 2$-derived recombinants, were produced and monitored for HD up to 20-weeks old (Table 1). D2.HD$\mathrm{F}_{2}$ recombinants developed $\mathrm{HD}$ at a rate of $2.9 \%(15 / 510)$, with no sex difference identified $(p=0.186)$. Twenty D2.HD- $\mathrm{N}_{2}$ mice (8.5\%) developed HD, with a 1.7 -fold difference $(p=0.017)$ between females $(13 / 122 ; 10.7 \%)$ and males $(7 / 112 ; 6.3 \%)$. As expected, because the same mutant male was used for the $\mathrm{F}_{1}$ and then the $\mathrm{N}_{2}$ crosses with daughters, the rates of affected D2.HD- $\mathrm{N}_{2}$ mice were 2.9 -fold that of D2.HD- $\mathrm{F}_{2}$ mice (8.5\% versus $\left.2.9 \%\right)$. The use of D2 mice increased the percentages of affected recombinants over B6 and S1 mice, consistent with our prediction that the lack of $\mathrm{C} 5$ has a direct or indirect role in $\mathrm{EM} / \mathrm{HD}$, possibly stemming from a more susceptible immune milieu in the absence of $\mathrm{C} 5$.

\section{Dysf}

For an additional strategy to improve the rate of generating recombinants developing HD and to identify regions significantly linked to the disease, we tested a parallel hypothesis that the known Dysf gene mutation in the A/ $\mathrm{J}$ strain (and thus the $\mathrm{A} / \mathrm{J}^{\mathrm{HD}}$ line) contributes to the mutant phenotype. Although the Dysf mutation in the A/J strain appears to be unique to this strain (a 5-6 kb ETn retrotransposon inserted into intron 4) [13], the SJL/J (SJ) inbred strain has a splice-site mutation in Dysf, resulting in a markedly decreased protein level [14]. Like the $\mathrm{A} / \mathrm{J}$ strain, the $\mathrm{SJ}$ strain is also considered a naturally occurring animal model for dysferlinopathy [15]. Consequently, all mice deriving from crosses of the SJ and A/ $\mathrm{J}^{\mathrm{HD}}$ strains will carry two mutated copies of the Dysf gene. Like the D2 crosses for mutant $C 5$, an increase in affected SJ-derived recombinants would indirectly support an involvement of mutant Dysf in the development, progression, and/or modification of the pathobiology associated with EM/HD.

Accordingly, the SJ-derived crosses were used to map the causal HD genes and test a potential contributing role for Dysf in EM/HD; again, the $\mathrm{N}_{2}$ and $\mathrm{F}_{2}$ mating schemes were exploited (Additional file 1, left). Cohorts of 287 intercross mice (SJ.HD- $\mathrm{F}_{2}$ ) and 98 backcross mice (SJ.HD- $\mathrm{N}_{2}$ ), for a total of 385 SJ-derived recombinants were produced and monitored up to 20-weeks old for HD (Table 1). SJ.HD-F 2 recombinants developed HD at a rate of $7.7 \%(22 / 287)$, with no sex difference observed (females: $10 / 139 ; 7.2 \%$ and males $12 / 148 ; 8.1 \% ; p=$ 0.348). Seventeen SJ.HD- $\mathrm{N}_{2}$ mice (17.3\%) developed HD, with a slight yet significant $(p=0.029)$ difference between females $(9 / 56 ; 16.1 \%)$ and males $(8 / 42 ; 19.0 \%)$. Again, the backcross breeding scheme produced HD at more than twice the rate of $F_{2}$ crosses $(17.3 \%$ versus 7.7\%). Consistent with our hypothesis of a contributing role for Dysf deficiency in EM/HD, the use of SJ-derived crosses dramatically increased the percentages of affected recombinants. Comparing these final crosses to the first 3 attempts (Additional file 1), the SJ.HD- $\mathrm{N}_{2}$ (17/ 98; 17.3\%) improved the rate of $\mathrm{HD} \sim 35$-fold over the combined B6 and S1 crosses (3/599; 0.5\%).

\section{QTL analysis}

Assessment of genetic linkage to the EM/HD trait was performed using R/qtl analysis $[16,17]$ to associate $\mathrm{HD}$ (binary trait: present or not by 20 -weeks old) with SNPs on the GigaMUGA SNP array generated for all affected and unaffected mice in the analyses. Each cross was analyzed separately and then combined with its alternative mating scheme partner (i.e., D2 crosses or SJ crosses).

\section{D2 crosses}

For the D2.HD- $\mathrm{N}_{2}$ analysis, a total of 19 affected (i.e., verified HD) and 6 unaffected (i.e., littermates that did not develop HD by 20 -weeks old) backcross mice were used. Similarly, 16 affected and 16 unaffected D2.HD- $F_{2}$ 
mice were utilized in a separate QTL analysis (Table 2). Except for the chromosome 2 area around $C 5$, the $\mathrm{F}_{2}$ population will help to rule out genomic regions that are homozygous D2 in affected mice.

Results of the D2.HD- $\mathrm{N}_{2}$ QTL analysis identified a suggestive linkage on distal chromosome $5(\mathrm{LOD}=3.32$; Fig. 3). Details of the peak markers, LOD scores, percent variance explained and QTL intervals for this and all other performed analyses are summarized in Table 2 . Initially, the results of the D2.HD- $\mathrm{N}_{2}$ cohort also indicated a suggestive locus on distal chromosome 17 (LOD $=3.39$; Fig. 3), but this peak was subsequently ruled out after determining the region coincided with residual B6 genome from the founder A.B6 congenic. Specifically, one of the $\mathrm{A} / \mathrm{J}^{\mathrm{HD}}$ breeder males used in the D2.HD- $\mathrm{N}_{2}$ crosses still contained a portion of the original B6 congenic interval. However, since HD occurred in mutant mice after removing the residual B6 interval, linkage to this region (and thus the QTL peak) was ruled out. Interestingly, neither the D2.HD- $\mathrm{F}_{2}$ analysis nor a combined (D2.HD- $\mathrm{N}_{2}+$ D2.HD- $\mathrm{F}_{2}$ ) analysis identified any locus that reached suggestive linkage (Additional file 2).

\section{SJ crosses}

Separate QTL analyses of SJ-derived $\mathrm{N}_{2}$ and $\mathrm{F}_{2}$ recombinants were performed and results are plotted in Fig. 4 and detailed in Table 2. The SJ.HD-N $\mathrm{N}_{2}$ recombinants (16 affected and 17 unaffected) found the same distal chromosome 5 QTL identified as a suggestive locus in the D2.HD- $\mathrm{N}_{2}$ population, but in this case, the SJ.HD$\mathrm{N}_{2}$ cohort was highly significant $(\mathrm{LOD}=4.88)$ and explained $47.4 \%$ of the trait variance. With this confirmation, we have designated the chromosome 5 linkage as Emhd1, for 'eosinophilic myocarditis to heart disease'. Interestingly, the SJ.HD-F 2 population (22 affected and 22 unaffected) did not identify the QTL on chromosome 5. Instead, a highly significant QTL was found on chromosome 17 (Fig. 4b). A closer look at the peak revealed two closely linked loci (Fig. 4c), including a locus proximal to MHC (LOD = 7.51; designated Emhd2) and another region that contained the $\mathrm{MHC}$ region $(\mathrm{LOD}=$ 6.89; named Emhd3). Each locus explained about 35\% of the trait variance. However, their proximity to each other, and the fact that all but two mice had both QTLs in heterozygosity indicated the variance explained by these QTLs almost entirely overlapped. Similarly, both chromosome 17 QTLs were consistent with dominant variants, such that only one mutant allele of each is required in the HD trait. There was no difference in survival of affected mice that were heterozygous $(n=20)$ and homozygous mutant $(n=2)$ genotypes for Emhd2-3.

The combined analysis of the 77 SJ-derived $\mathrm{N}_{2}$ and $\mathrm{F}_{2}$ recombinants (38 affected and 39 unaffected) identified all three Emhd peaks (Table 2; Additional file 3). LOD scores were like those from the separate populations, demonstrating the utility of the separate SJ mating schemes to

Table 2 QTLs identified in R/qtl analyses

\begin{tabular}{|c|c|c|c|c|c|}
\hline $\begin{array}{l}\text { Cross } \\
\text { (\#HD / \#Unaffected) }\end{array}$ & $\begin{array}{l}\text { Chr position } \\
\text { (@ peak SNP) }\end{array}$ & LOD Score & $\%$ Variance Explained & Level of Significance $^{a}$ & $\begin{array}{l}\text { Haplotype-defined interval } \\
\text { Chr: Mb range (size of interval) }\end{array}$ \\
\hline $\begin{array}{l}\text { D2.HD- } \mathrm{N}_{2} \\
(19 / 6)\end{array}$ & 5:147147276 & 3.32 & 43.2 & suggestive & $\begin{array}{l}\text { 5:143159090-151734385 } \\
(8.58 \mathrm{Mb})\end{array}$ \\
\hline $\begin{array}{l}\text { D2.HD-F } \\
(16 / 16)\end{array}$ & - & - & - & - & $\begin{array}{l}\text { 5:144329217-147894899 } \\
(3.57 \mathrm{Mb})\end{array}$ \\
\hline $\begin{array}{l}\text { SJ.HD-N } 2 \\
(16 / 17)\end{array}$ & 5:148558183 & 4.88 & 47.4 & $\begin{array}{l}\text { highly significant } \\
\text { (Emhd1) }\end{array}$ & $\begin{array}{l}\text { 5:129525220-151734385 } \\
(22.21 \mathrm{Mb})\end{array}$ \\
\hline \multirow[t]{3}{*}{$\begin{array}{l}\text { SJ.HD-F } \\
(22 / 22)\end{array}$} & - & - & - & - & $\begin{array}{l}\text { 5:145128608-147778059 } \\
(2.65 \mathrm{Mb})\end{array}$ \\
\hline & 17:21456192 & 7.51 & 52.9 & $\begin{array}{l}\text { highly significant } \\
\text { (Emhd2) }\end{array}$ & $\begin{array}{l}\text { 17:15358323-23816187 } \\
(8.46 \mathrm{Mb})\end{array}$ \\
\hline & 17:35308100 & 6.89 & 49.6 & $\begin{array}{l}\text { highly significant } \\
\text { (Emhd3) }\end{array}$ & $\begin{array}{l}\text { 17:31471362-46058209 } \\
(14.59 \mathrm{Mb})\end{array}$ \\
\hline \multirow[t]{4}{*}{$\begin{array}{l}\text { SJ.HD-N } \mathrm{N}_{2}+\mathrm{F}_{2} \\
(38 / 39)\end{array}$} & 1:176044015 & 4.12 & 21.3 & significant & $\begin{array}{l}\text { 1:172969406-194625219 } \\
(23.59 \mathrm{Mb})\end{array}$ \\
\hline & 5:146601763 & 5.79 & 28.6 & $\begin{array}{l}\text { highly significant } \\
\text { (Emhd1) }\end{array}$ & $\begin{array}{l}5: 143159090-151734385 \\
(8.58 \mathrm{Mb})\end{array}$ \\
\hline & 17:17933928 & 6.53 & 35.1 & $\begin{array}{l}\text { highly significant } \\
\text { (Emhd2) }\end{array}$ & same as $F_{2}$ \\
\hline & 17:35308100 & 7.43 & & $\begin{array}{l}\text { highly significant } \\
\text { (Emhd3) }\end{array}$ & same as $F_{2}$ \\
\hline
\end{tabular}

All genomic positions are based on mm10 (GRCm38; Build 38). Genotyping of > 143,00 SNPs was performed by GeneSeek (Lincoln, NE) using the GigaMUGA SNP panel. Separate QTL analyses were run for each cross using R/qtl $[16,17]$ after applying argyle routines for quality checks [18]. Combined SJ crosses were analyzed as an $F_{2}$ model $(0,1,2)$, accepting the limitations. ${ }^{\text {a }}$ Significance was determined using 1000 permutations of the corresponding dataset. QTL intervals were determined using haplotype analysis, in which we identified the proximal and distal crossovers that best correlated the genotype with phenotype 


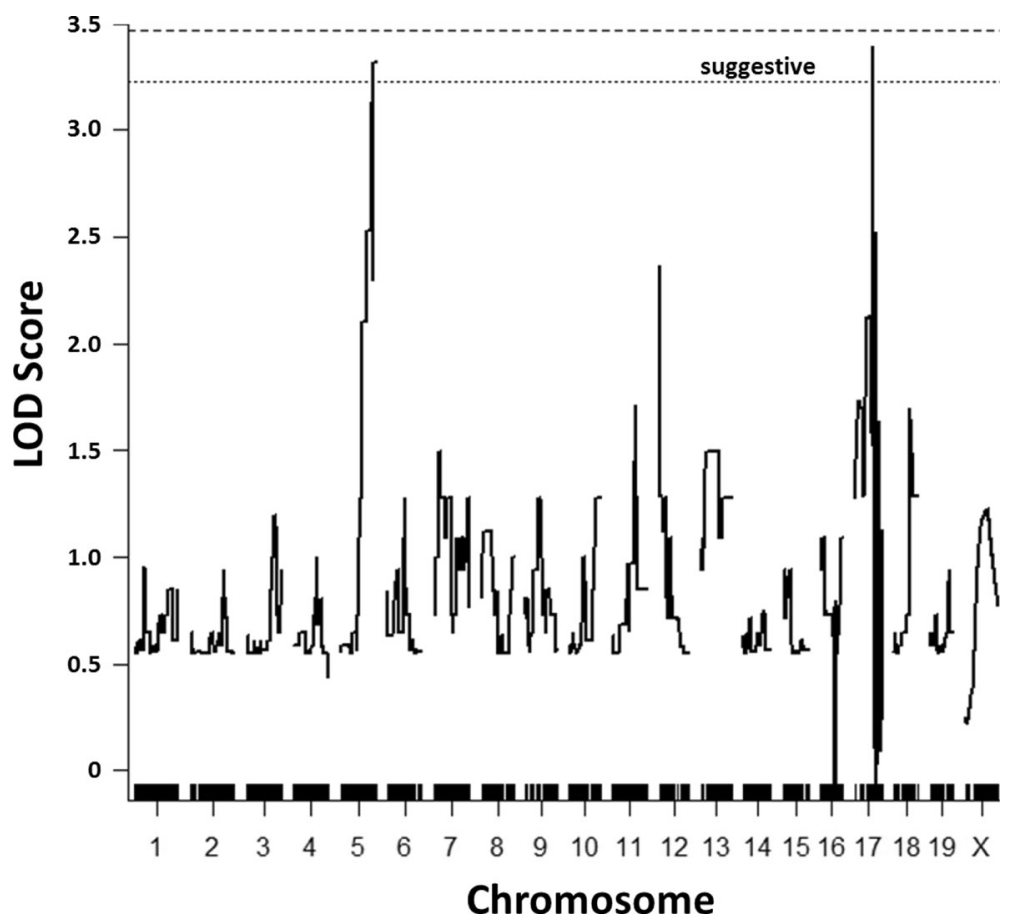

Fig. 3 QTL analysis results of the D2.HD-N 2 cohort. Regions on chromosomes 5 and 17 were suggestive of linkage $(p<0.67)$, with LOD scores of 3.32 and 3.39, respectively. The chromosome 17 locus was later ruled out. The D2.HD-F $F_{2}$ crosses did not identify linkage. $n=25$ (19 affected, 6 unaffected); D2 = DBA/2 J

detect recessive versus dominant linkage for this complex trait: the backcrosses identified the recessive Emhd1 on chromosome 5 and the $F_{2}$ crosses found the dominantacting Emhd2 and Emhd3 on chromosome 17. The height of the Emhd2 and Emhd3 peaks flipped in the combined analysis compared with the SJ.HD- $\mathrm{F}_{2}$ but were still highly significant. We next tested for a possible interaction between the QTLs using the scantwo function of R/qtl. In a 2-QTL model for the chromosome 5 and chromosome 17 (which was treated as one locus) QTLs, the scantwo LOD score was additive (13.2) with no signs of epistasis (LOD = $1.02)$, and the variance explained (53.6\%) increased only slightly. In addition to these three Emhd loci, analysis of this combined SJ.HD- $\mathrm{N}_{2}+\mathrm{F}_{2}$ dataset also revealed a putative significant linkage on distal chromosome 1 (LOD = 4.12; Additional file 3A), which was not seen in any of the separate cohorts. However, one can easily see that this peak derives from the smaller peaks at similar positions in the separate analyses (Fig. 4a, b); this locus will require further assessment to determine its involvement.
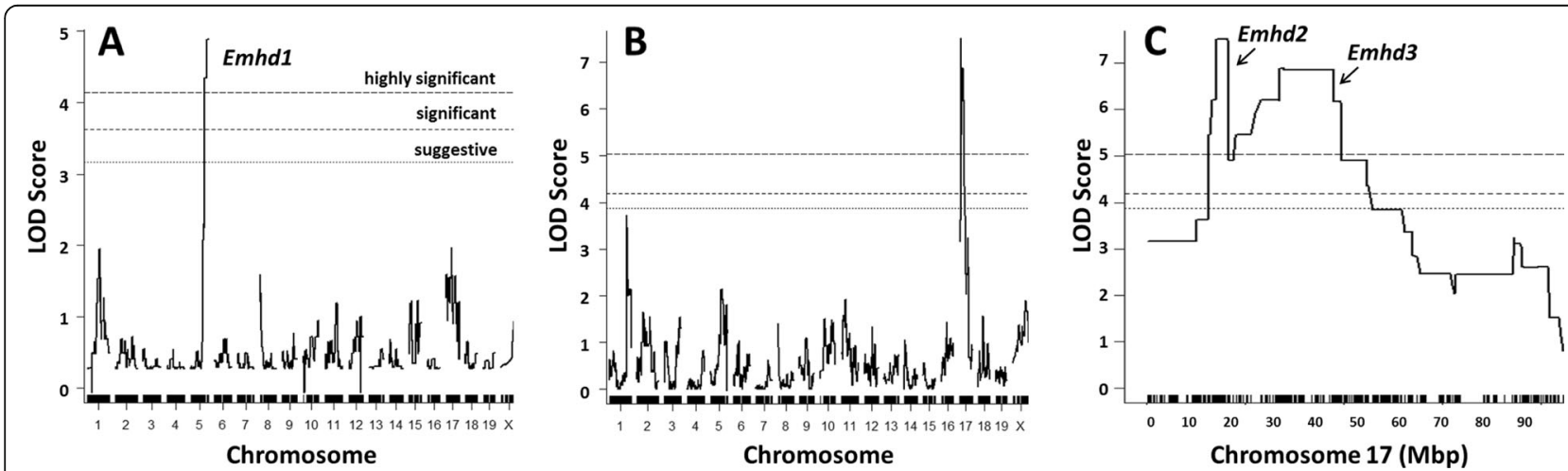

Fig. 4 QTL analysis results of the SJ.HD crosses. a SJ.HD- $N_{2}(n=33 ; 16$ affected, 17 unaffected); b SJ.HD-F $(n=44 ; 22$ affected, 22 unaffected); and $\mathbf{c}$ A closer view of the chromosome 17 peak in B $\left(S J . H D-F_{2}\right)$, indicating two distinct QTL peaks. SJ $=S J L / J$. Suggestive $(p<0.67)$, significant $(p<0.05)$ and highly significant $(p<0.01)$ thresholds for linkage are as indicated in A and determined by 1000 permutations of the respective datasets 


\section{Haplotype analysis and concordance}

Using the Excel file of SNP genotypes for all mice with HD and unaffected littermates used in the mapping cohorts, the heterozygous and both homozygous genotypes were color-coded to visually perform haplotype analysis (Additional file 4). This color-coding allowed us to quickly scan the genomewide SNPs, with specific focus on linkage regions, to identify recombinant mice with crossovers that delineated the three QTL intervals. Figure 5 presents an overview of the haplotype analysis results. For the recessive Emhd1 minimal region of effect, heterozygous SJ.HD- $F_{2}$ recombinants determined the proximal and distal ends of the QTL, whereas the bracketed intervals of the dominant Emhd2 and Emhd3 QTLs were defined by homozygous SJ alleles in affected SJ.HD-F $F_{2}$ recombinants. Backcrosses, which carry at least one copy of the QTLs from the mutant breeder, are necessarily concordant for a dominant mutation (Additional file 5), and thus are uninformative for defining the QTL intervals of Emhd2 and Emhd3. Concordance for dominant loci was therefore assessed in $\mathrm{F}_{2}$ mapping cohorts.

\section{Emhd1}

The single B6.HD- $\mathrm{N}_{2}$ recombinant (1/50) and the two of 226 S1.HD- $\mathrm{F}_{2}$ recombinants that died of HD (Additional file 1) all carried homozygous $\mathrm{A} / \mathrm{J}^{\mathrm{HD}}$-derived genome across Emhd1. Among the D2- and SJ-derived recombinant populations, haplotype analysis for Emhd1 determined large differences in the size of the chromosome 5 interval
(Table 2). Specifically, the Emhd1 interval spanned 22.21 $\mathrm{Mb}$ in the SJ.HD- $\mathrm{N}_{2}$ population $(n=33)$, which was reduced to $8.58 \mathrm{Mb}$ in the D2.HD- $\mathrm{N}_{2}$ cohort $(n=25)$, to $3.57 \mathrm{Mb}$ for the D2.HD- $\mathrm{F}_{2}$ recombinants $(n=32)$, and finally down to $2.65 \mathrm{Mb}(145.13-147.78 \mathrm{Mb})$ in the SJ.HD$\mathrm{F}_{2}$ population $(n=44)$. Of note, while neither $\mathrm{F}_{2}$ cohort identified linkage to Emhd1, individual recombinants of both $F_{2}$ cohorts significantly refined the QTL interval of their respective $\mathrm{N}_{2}$ populations. The genotypes of all affected SJ.HD- $\mathrm{F}_{2}$ recombinants were concordant with $\mathrm{HD}$ across the defined QTL interval (i.e., 22/22 homozygous for mutant $\mathrm{A} / \mathrm{J}^{\mathrm{HD}}$ alleles). However, 3 of $16 \mathrm{D} 2 . \mathrm{HD}-\mathrm{F}_{2}$ affected recombinants were discordant $(1=$ heterozygous, and 2 =homozygous D2) for the expected homozygous mutant alleles at Emhd1 (Additional file 5). Among the unaffected SJ recombinant mice in the analysis, Emhd1 showed the expected 1:1 ratios of heterozygous or homozygous alleles in the $\mathrm{N}_{2}$ cohort and ratios of 1:2:1 in the unaffected $\mathrm{F}_{2}$ littermates. These data strongly support that Emhd1 is necessary, but not sufficient to cause EM/HD in this mutant.

\section{Emhd2}

Haplotype analysis of the D2 crosses for Emhd2 was not possible, because $\mathrm{D} 2$ and $\mathrm{A} / \mathrm{J}$ inbred strains are identical-by-descent (IBD) for the proximal $\sim 28.65 \mathrm{Mb}$ of chromosome 17. However, haplotype analysis of the affected SJ.HD-F $F_{2}$ recombinants revealed specific crossovers that defined the proximal and distal ends of Emhd2, which confined the Emhd2 to an $8.46 \mathrm{Mb}$ region

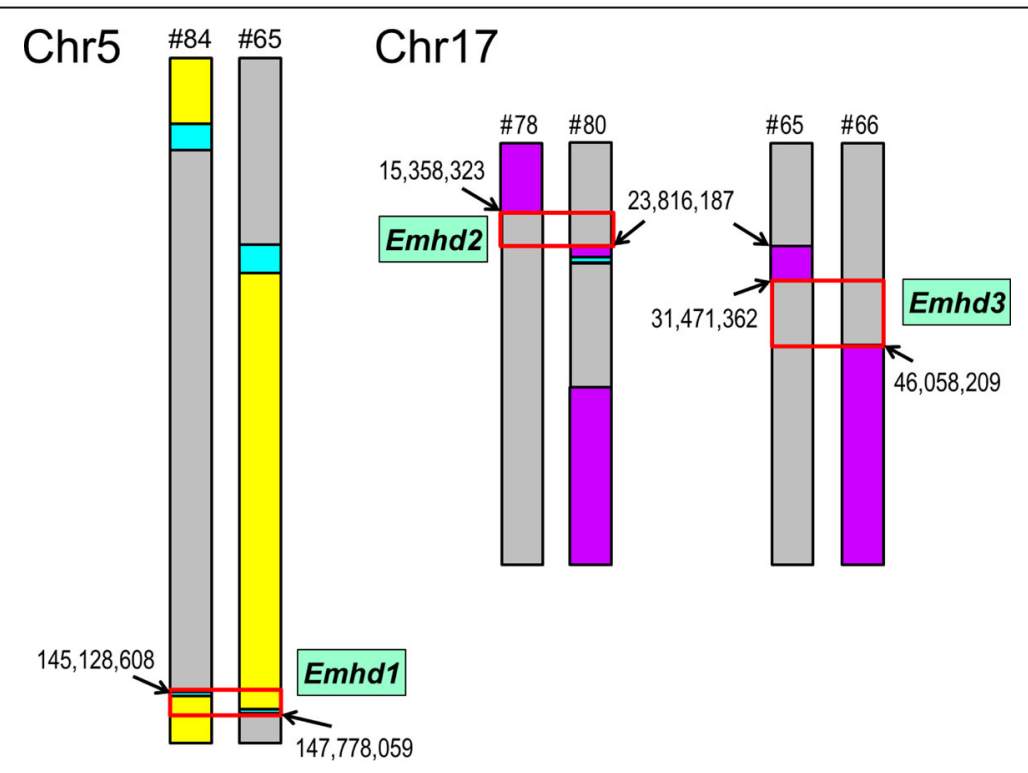

Fig. 5 QTL locations and sizes. Haplotype results of the three highly significant Emhd QTL intervals (red boxes). Chromosome (Chr) 5 and Chr17 (presented as diploid) of individual numbered recombinants (\#) with key crossovers that demarcate the proximal and distal boundaries of each QTL interval. Arrows indicate the SNP positions (GRCm38; Build 38) of each crossover. Yellow = homozygous A/J $J^{\text {HD }}$; Purple = homozygous SJ; Gray = heterozygous; Cyan = identical by descent 
(15.36-23.82 Mb; Fig. 5, Table 2) on chromosome 17. This interval maps proximal to the $\mathrm{MHC}$ region. All affected SJ.HD-F ${ }_{2}$ mice (22/22) were concordant for a dominant variant (Additional file 5). In contrast, 8/22 unaffected SJ.HD- $\mathrm{F}_{2}$ recombinants were discordant (i.e., no mutant alleles), which is consistent with the expectation of $\sim 1 / 4$ homozygosity $(p=0.36)$ for SJ alleles in $\mathrm{F}_{2}$ crosses.

\section{Emhd3 and putative QTL on chromosome 1}

Haplotype analysis of the 22 SJ.HD-F 2 affected mice revealed specific crossovers that defined the proximal and distal ends for Emhd3. As illustrated in Fig. 5, the Emhd3 interval was mapped to a $14.59 \mathrm{Mb}$ region (31.47-46.06 Mb; Table 2) on chromosome 17 that includes the major histocompatibility genes and several complement genes of the alternative pathway. All 22 SJ.HD-F ${ }_{2}$ recombinant mice with $\mathrm{HD}$ used in the QTL analysis were concordant for a dominant variant (Additional file 5). In addition, the same 8/22 unaffected SJ.HD-F 2 recombinants that were discordant for Emhd2 were also discordant for Emhd3 (i.e., homozygous for SJ alleles throughout both QTL intervals).

Haplotype analysis was also used to determine the interval size of the putative linkage on chromosome 1 (Table 2). Because the genotypes were consistent with a dominant variant (backcrosses are uninformative), only the $F_{2}$ data were used. All 22 SJ.HD-F 2 affected mice were concordant for a $23.59 \mathrm{Mb}$ interval ranging from $\sim 171.04-194.63 \mathrm{Mb}$ on distal chromosome 1 . Interestingly, the D2.HD- $\mathrm{F}_{2}$ cohort was highly discordant (i.e., up to $10 / 16$ affected $F_{2}$ mice were homozygous for D2 alleles across all (6/16) or a large portion $(4 / 16)$ of this putative chromosome 1 interval, with at least 7/16 affected mice carrying homozygous D2 alleles at every SNP across the interval). This discordance could indicate the chromosome 1 linkage supported by SJ.HD-F 2 recombinants was a false positive. However, it is also possible that this putative QTL represents a distinction in the set of contributing causal variants for HD between the SJ and D2 crosses.

\section{Positional candidate genes}

Using the Genes and Markers query form in MGI (The Jackson Lab; http://www.informatics.jax.org/marker), we generated lists of all 'gene feature types' mapping to the genetic intervals of the three Emhd and putative chromosome loci, as determined by haplotype analysis. After removing transcription start sites and $\mathrm{CpG}$ island sites, lists of the remaining genetic elements mapping to each of the haplotype-derived QTL intervals were generated, and results were itemized into 8 general categories for reference (Additional file 6). Using literature searches for keywords like heart disease, heart failure, immune dysfunction (including autoimmunity), inflammation, chemokine and cytokine changes, eosinophil pathobiology or coagulopathy, biologically-relevant positional candidates were identified from the known protein coding genes mapping to the highly significant Emhd loci. These positional candidate genes were further evaluated through the International Mouse Phenotyping Consortium database (www.mousephenotype.org) to determine possible gene associations with disease. Top candidates are listed in Table 3 and represent potential starting points for follow-on studies.

\section{Discussion}

We have established an inbred mutant line from a founder mouse discovered in the colony. Without a known initiating factor or trigger, affected mice develop EM that progresses to HD and death. We recently reported a detailed histological evaluation of the hearts and lungs of these mutant mice [2]. In these studies, we did not see significant variance of this heart pathology among the affected mice of the different crosses. Although affected mice die with a failing heart, the cardiac pathology was heterogenous. However, these differences can all be ascribed to the spectrum of injuries related to blood and tissue eosinophilia, especially EM and its consequences. In fact, the affected mutant mice present with pathognomonic features of several eosinophil-associated diseases, including natural or induced (e.g., pathogen or autoimmune) EM, hypereosinophilic syndrome (HES) with cardiac complications [31], and eosinophilic granulomatosis with polyangiitis (EGPA; aka Churg-Strauss Syndrome) [32].

Because the eosinophil-associated diseases with heart complications are complex and rare, with few reports demonstrating a familial etiology, little is known regarding the specific genetic determinants involved. Accordingly, genetic analysis for these complex diseases in clinical populations would be difficult, costly, and unlikely to provide the power needed for multigenic discovery. In contrast, the ability to maintain our mutant mouse model of $\mathrm{EM} / \mathrm{HD}$ for many years strongly supported that the genetic underpinnings of this mutant model were not too complex, and therefore offered an opportunity to map this disease. Two additional findings indicate that HD in this mutant line is controlled by a small set of causal factors. First, we reestablished the original EM/HD trait after several backcrosses and intercrosses to remove the congenic region from the founder; this process recapitulated the disease in an inbred $\left(\mathrm{A} / \mathrm{J}^{\mathrm{HD}}\right)$ line. Second, mapping studies have revealed three highly significant QTLs, with each locus explaining a significant portion of the trait variance in the relevant crosses. Up to $64 \%$ of the variance was explained by a 2-QTL model that included Emhd1 and either Emhd2 or Emhd3, indicating the effects on variance by the two closely mapped chromosome 17 QTLs were not separable in the analysis. These data demonstrate that $\mathrm{EM} / \mathrm{HD}$ in this mutant line involves the interactions of a 
Table 3 Positional Candidate Genes for Emhd1-3

\begin{tabular}{|c|c|c|c|}
\hline Gene & Name & Position Bld38 & Example of Possible Biological Relevance \\
\hline \multicolumn{4}{|c|}{ Emhd1 (Chr5: 145128608 - 147778059): 46 known protein-coding genes } \\
\hline Arpcib & Actin related protein $2 / 3$ complex, subunit $1 B$ & $145,114,256-145,128,186$ & $\begin{array}{l}\text { deficiency associated with severe inflammation, } \\
\text { immunodeficiency, and cardiac vasculitis [19] }\end{array}$ \\
\hline Cdk8 & Cyclin-dependent kinase 8 & $146,231,230-146,302,874$ & $\begin{array}{l}\text { ectopic expression of Cdk8 induces eccentric } \\
\text { hypertrophy and heart failure [20] }\end{array}$ \\
\hline Flt1 & FMS-like tyrosine kinase 1 & $147,562,196-147,726,005$ & $\begin{array}{l}\text { increased cardiac remodeling in cardiac-specific } \\
\text { Flt1 receptor knockout mice [21] }\end{array}$ \\
\hline Flt3 & FMS-like tyrosine kinase 3 & $147,330,741-147,400,489$ & $\begin{array}{l}\text { activation improves post-myocardial infarction } \\
\text { remodeling by protective effect on cardiac cells [22] }\end{array}$ \\
\hline $\operatorname{Ln} \times 2$ & Ligand of numb-protein $\times 2$ & $147,016,655-147,076,572$ & $\begin{array}{l}\text { affects T-cell-mediated immune responses by } \\
\text { regulating level of the T-cell co-receptor, CD8a [23] }\end{array}$ \\
\hline \multicolumn{4}{|c|}{ Emhd2 (Chr17: 15358323 - 23816187): 61 known protein-coding genes } \\
\hline D/11 & Delta-like canonical Notch ligand 1 & $15,367,354-15,376,048$ & $\begin{array}{l}\text { increased serum levels associated with diastolic } \\
\text { dysfunction, reduced exercise capacity, and } \\
\text { adverse outcome in chronic heart failure [24] }\end{array}$ \\
\hline Ppp2r1a & $\begin{array}{l}\text { Protein phosphatase } 2 \text {, regulatory subunit } \\
\text { A, alpha (PP2A) }\end{array}$ & $20,945,454-20,965,905$ & requisite for the function of regulatory $T$ cells [25] \\
\hline Tnfrsfi2a & TNF receptor superfamily, member 12a (fn14) & $23,675,445-23,677,449$ & $\begin{array}{l}\text { a novel role in the development of cardiac } \\
\text { dysfunction and failure [26] }\end{array}$ \\
\hline \multicolumn{4}{|c|}{ Emhd3 (Chr17: 31471362 - 46058209): 261 known protein-coding genes } \\
\hline$C 2, C 4 a, C 4 b, C f b$ & $\begin{array}{l}\text { Complement components } 2,4 a, 4 b \text {, and } \\
\text { factor b (alternative pathway) }\end{array}$ & between 34.728-34.882 & $\begin{array}{l}\text { the alternative complement pathway is dysregulated } \\
\text { in patients with chronic heart failure [27] }\end{array}$ \\
\hline H2 genes & $\sim 3$ dozen MHC genes & between33.996-37.275 & $\begin{array}{l}\text { a humanized HLA-DR4 mouse model for autoimmune } \\
\text { myocarditis [28] }\end{array}$ \\
\hline Tnf & Tumor necrosis factor & $35,199,381-35,202,007$ & $\begin{array}{l}\text { cardiac-specific overexpression causes lethal } \\
\text { myocarditis in transgenic mice [29] }\end{array}$ \\
\hline Tnfrsf21 & TNF receptor superfamily, member 21 & $43,016,555-43,089,188$ & $\begin{array}{l}\text { KO mice show increased Th2 immune responses to } \\
\text { T-dependent and -independent antigens [30] }\end{array}$ \\
\hline
\end{tabular}

limited number of causal factors, for which three highly significant QTLs explain a majority of the trait variance. However, as the 3 QTLs do not account for full penetrance, additional factors such as other gene variants or an environmental factor (e.g., a pathogen or microbiome) may be needed to explain the missing heritability.

To map a disease trait, recombinants from crossing the mutant with another strain must recapitulate all or an essential part of the original trait of interest. Success depends on the number of variants involved in the trait (which is related to penetrance), the mode and direction of inheritance of each mutation, and any non-genetic and/or environmental confounders. The observed rate of affected recombinants depends on the allelic combinations of fixed and segregating causal variants carried between each mating pair. For the $\mathrm{A} / \mathrm{J}^{\mathrm{HD}}$ inbred line, the rates of affected offspring ranged from zero for many breeder pairs to $>50 \%$ of offspring developing HD for some mating pairs. Based on the variable rates of affected mice over several years of line maintenance, we estimated $\sim 2-3$ variants were likely segregating for the $\mathrm{HD}$ trait in the $\mathrm{A} / \mathrm{J}^{\mathrm{HD}}$ line.

To indirectly examine the disconnect between affected rates seen in the $\mathrm{A} / \mathrm{J}^{\mathrm{HD}}$ line versus the few affected mice in the initial three mapping populations, we tested Dysf (SJ crosses) and/or C5 (D2 crosses), two genes with biological relevance to our trait and known to be lacking in A/J mice. DYSF deficiency causes dysferlinopathy [33, 34] and leads to defective membrane resealing in skeletal muscle and to muscle necrosis [35]. DYSF is also involved in cardiomyocyte membrane repair and its deficiency leads to cardiomyopathy in Dysf null mice [36, 37]. Therefore, it is plausible that the reduced cardiac repair capacity with Dysf deficiency in $\mathrm{A} / \mathrm{J}^{\mathrm{HD}}$ mice contributes to the HD, similar to that associated with other muscular dystrophies [38]. Lack of C5 has also been associated with cardiac failure, but usually after a viral [39], fungal [5, 40] or protozoal [41] infection. Interestingly, it was recently reported that DYSF deficiency leads to increased susceptibility to coxsackievirus B3 (CB3)-induced cardiomyopathy in C5deficient $\mathrm{A} / \mathrm{J}$ mice and suggested an important mechanism of DYSF cleavage by viral proteases underpinning cardiac dysfunction [42]. Importantly, although only 3 affected mice of 599 total recombinants were generated from the S1 and B6 crosses, all 3 of these mice were homozygous for Dysf mutant alleles and mutant alleles for Dysf and 2 of 3 were homozygous for mutant C5 alleles, with the 
third (i.e., one of the $\mathrm{S} 1 \mathrm{~F}_{2}$ mice) being heterozygous for C5. This data, combined with the significant increase in rates of affected mice observed in SJ and D2 crosses, indicates the need for direct studies to understand the role for $D y s f$ and/or $C 5$ deficiency in EM/HD.

Many studies have sought to understand the complex genetic control of myocarditis. These studies can be classified by many factors, including spontaneous versus induced; acute versus chronic; type of inducing agent (e.g., pathogen - viral, bacterial or fungal, drug/toxin, or adjuvant); innate, adaptive, and autoimmunity; cellular infiltrate and/or cells affected; and natural animal model versus engineered. Sorting through these studies, we have determined that our mutant mouse model of EM/ HD is unique. Prior to our discovery, at least 3 mouse models were known to spontaneously develop EM, including the D2 inbred strain [43], and Socs1 [44] or Bcl6 knockout (KO) mice [45]. All other EM models are induced, e.g., cardiac myosin peptides: $\mathrm{IL}_{17 \mathrm{~A}^{-/-}} \mathrm{IFN \gamma}{ }^{-/-}$ double knockout [46] or the SWXJ, SJ, or SWR/J mice [47]; or with a pathogen (e.g., CB3 [39, 48]). But, unlike D2 mice that resolve the spontaneous EM by $\sim 8-10$ weeks old [49], the naturally-occurring EM of our mutant line rapidly progresses through myocardial damage, inflammation and thrombotic events that can cause sudden cardiac death or progress to DCM and fatal HD. These outcomes differed from other mouse models of spontaneous EM [43-45] and parallel the more egregious pathologies in HES and EGPA patients. Interestingly, a combined KO-transgenic mouse model generated with human HLA receptor (e.g., HLA DQ8.NOD A $\beta$ o) spontaneously develops myocarditis and DCM [50-52], but this myocarditis was not related to eosinophil damage. Thus, in addition to its use as a genetic resource, our mouse model is unique for presenting a spontaneous fatal EM due to cardiac manifestations. As such, the mutant line also provides a means to compare with other models of myocarditis to understand differentiating biological and pathological roles of the eosinophil in the progression from myocarditis to HD, and to understand differences in disease susceptibility and initiation (natural/induced) between models.

Lending validity to our QTL findings, the two putative QTLs we identified on chromosome 17 coincide with previously reported loci in a CB3-induced mouse model of chronic autoimmune myocarditis [53]. In that report, the B6.A-17 chromosome substitution strain [54] was found to confer susceptibility to CB3-induce myocarditis. The genetic background of B6.A-Chr17 mice is inbred B6, except for the A/J-derived chromosome 17 . These B6.A-Chr17 consomic mice were bred to produce various chromosome 17 congenic lines carrying different portions of chromosome 17 to use as recipient strains for viral-induced myocarditis. The study identified four regions on chromosome 17 harboring susceptibility loci for CB3-induced myocarditis, including an MHC locus and 3 putative loci proximal or distal to the MHC complex. The distal locus on chromosome 17 was ruled out in our mutant model, because many recombinants with EM/ HD carried homozygous SJ alleles across that region. The other three loci could coincide with the Emhd2 (upstream of MHC genes) and Emhd3 (this large region may house more than one QTL) intervals. Two differences between these models are clear: (1) our model of myocarditis, as far as we know, does not require induction and (2) the EM/HD mutant primarily involves an eosinophilic infiltration that causes cardiac inflammation, whereas the CB3induced myocarditis is characterized by a diffuse mononuclear interstitial infiltrate [55]. We suspect that the non-chromosome 17 locus Emhd1 on chromosome 5 could help explain at least some of the difference, especially regarding the role of eosinophils or susceptibility of the heart to eosinophilic infiltration.

Two limitations for these studies also need mentioning. First, as stated above, D2 mice spontaneously develop a non-lethal course of EM at a very young age, which usually resolves by 10 -weeks old [43]. Therefore, it is possible that some of the D2-related recombinants dying of HD were confounded by this early-age EM and the susceptibility alleles gained in the crosses with $\mathrm{A} / \mathrm{J}^{\mathrm{HD}}$. This could also explain why the D2 data was less effective at identifying significant linkage. Similarly, this confounder could be the reason why $3 / 16$ D2.HD- $F_{2}$ mice were discordant at Emhd1, whereas all other $\mathrm{N}_{2}$ and $\mathrm{F}_{2}$ mice with $\mathrm{HD}$ carried homozygous $\mathrm{A} / \mathrm{J}^{\mathrm{HD}}$ mutant alleles (Additional file 5). One could speculate that the Emhd1 causal variant resides in a gene or pathway involved in the resolution of EM in D2 mice. Second, the 'unaffected mice' used in these studies were littermates that did not show any signs of illness at sacrifice ( 20-weeks old). However, we had several breeders used to generate the recombinant populations that died of HD much later than 140 days old. Therefore, the 'unaffected' designation does not account for the possibility that they would have developed HD later.

Although our mouse model of spontaneous EM/HD and the spontaneous EM of inbred D2 mice [43] are clearly heritable, EM does not run in families. In fact, when multiple family members are affected it is usually due to a common infection (e.g., CB3) [48] or an unknown environmental exposure. Therefore, the relevance of mouse models to the genetics of human EM is not clear. To the contrary, significant evidence for heritability of several eosinophilia-related diseases has been published, but few genes are directly implicated. Familial HES is thought to be inherited in an autosomal dominant manner [56]. The heritability of most eosinophil-related disorders, however, is predicted to be multifactorial (many genes plus an environmental component), including EGPA [57], asthma [58], and the eosinophilic gastrointestinal disorders [59]. It is in this realm of 
multigenic eosinophil-related diseases that our mouse model of EM/HD seems to fit. For example, the likelihood that someone with hypereosinophilia will develop HD (the most fatal component of the disease) has a genetic basis (i.e., HLA-Bw44) [60]. Therefore, it is possible that our oligogenic mouse model features two distinct disease states that include both eosinophilia and the susceptibility of the heart to eosinophilia, thereby representing a model that can delineate the genetic factors for each.

\section{Conclusion}

Using crosses of four inbred strains with $\mathrm{A} / \mathrm{J}^{\mathrm{HD}}$ mutant males we generated eight different recombinant cohorts of $\mathrm{N}_{2}$ and $\mathrm{F}_{2}$ mice to recapitulate the EM/HD trait for linkage analysis. This methodical progression dramatically improved efficiency to produce offspring with HD from 0 to $>17 \%$, which was critical for mapping this oligogenic trait. QTL analysis of cohorts of affected recombinants and siblings with no HD by 20 -weeks old revealed three highly significant QTLs that can explain nearly two-thirds of the genetic variance. The consistent $>2$-fold increase in affected D2 and SJ recombinants, suggests Dysf (or another SJ variant, or SJ pathology in common with $\mathrm{A} / \mathrm{J}$ ) and lack of C5 (or other D2 change in common with A/J) may also have unknown modifying roles in susceptibility to EM/ HD and could help explain the remaining missing heritability. As few genes for eosinophil-related diseases are known in mouse or man, finding the causal genes that can explain this mouse model of EM/HD would allow directed studies to reveal pathological mechanisms and understand disease history, with a goal to interrogate potential translation to relevant human diseases.

\section{Methods}

\section{Mice}

All common inbred mouse strains were obtained from the Jackson Laboratory (JAX: Bar Harbor, ME) and all lines and crosses generated and used in these studies were derived from these original inbred strains. Mice were housed within a specific pathogen free AALAC approved facility at Cincinnati Children's Hospital. Mice were placed in shoebox containers with corncob bedding at up to 4 animals per cage, and a 12-h on/12-h off light/dark cycle. Animals were checked daily by Veterinary Services, including routine husbandry and cage changes, as well as daily status checks by a Compliance Technician. Laboratory staff performed routine monitoring of the colony at least 3 times a week, including necessary matings, weanings, ear tagging, phenotype observation, and animal sacrificing, as needed. Mice found to be ungroomed, immobile, dyspneic, cyanotic, or showing other signs of distress or illness were used or sacrificed promptly, usually that day. When identified by Veterinary Services staff, they send a text message directly to the PI and an email to staff, alerting us of a 'sick' mouse. Because mice usually do not show signs of illness until late in disease, usage of sick mice is addressed at that time - mice are sacrificed by Veterinary Services staff or, if needed by the lab, taken to necropsy for immediate use or sacrifice to obtain biological specimens. On weekends, the PI is called for instructions on how to handle the sick mouse (usually sacrificed by Veterinary Services staff). Moribund mice that were sacrificed and all mice found dead were visually assessed to verify HD. Recombinant mice were deemed 'unaffected' if they survived to 140 -days old ( 20 weeks) without signs of disease, a time when most affected mutant mice developed HD. All experimental mice used in these studies, including unaffected mice, were sacrificed by $\mathrm{CO}_{2}$ or isoflurane inhalation overdose before sample collections (e.g., tail clip, blood, tissue, and organ samples collected, as needed). All mice found moribund were used immediately or sacrificed by $\mathrm{CO}_{2}$ inhalation. Protocols were reviewed and approved by the Cincinnati Children's Hospital Institutional Animal Care and Use Committee (IACUC protocol \#2016-0048 to DRP), which required annual renewals and a total rewrite every 3 years.

\section{Discovery of the mutant line}

The founder mutant mouse was initially found in an A.B6Chr17 congenic line already in the colony for another purpose. The genetic background of the A.B6-Chr17 congenic was inbred $\mathrm{A} / \mathrm{J}$, except for a $\sim 45-\mathrm{Mb}$ region of C57BL/6 J (B6) introgressed onto distal chromosome 17 (as verified by the MegaMUGA SNP panel; GeneSeek, Neogen Genomics; Lincoln, NE). To determine whether the chromosome 17 congenic B6 interval contributed to the mutant trait, the $\mathrm{B} 6$ congenic region was removed by backcrossing with inbred A/J mice (JAX stock \#000646), intercrossing first-generation siblings (A/J with a heterozygous congenic interval) and genotyping the second-generation offspring for microsatellite markers (IDT; Coralville, IA) polymorphic for $\mathrm{A} / \mathrm{J}$ and $\mathrm{B} 6$ that spanned the congenic interval. Following the removal of the B6 congenic interval, the $\mathrm{A} / \mathrm{J}$ inbred status of the mutant line was again verified using the Illumina-based MegaMUGA panel of $\sim 77,800$ SNPs (GeneSeek). Importantly, after reestablishing the A/J inbred background, we were able to recapitulate EM/HD $\left(\mathrm{A} / \mathrm{J}^{\mathrm{HD}}\right)$, but only after several breeder pairs and multiple litters from each pairing, suggesting more than one gene was still segregating for the trait. Generating mice that developed EM/HD after the congenic interval was removed verified that the B6 interval (and the A/J complement region that replaced it) was not contributing to the mutant trait. To help ensure that we retain the causal alleles in the gene pool, numerous sibling-sibling or offspring-parent mating pairs are maintained at each generation to propagate the trait. Successfully reestablishing EM/HD in the inbred line not only demonstrated trait heritability but suggested that its mode of inheritance was not overly complicated. 


\section{Phenotype}

The full characterization of the mutant $\mathrm{A} / \mathrm{J}^{\mathrm{HD}}$ line has recently been described [2]. In that report, the mutant line is referred to as AJ.EM, since EM was the primary early histological finding. The diseased heart develops a profuse EM and inflammatory dilated cardiomyopathy (DCM), often with considerable right ventricular outer wall expansion to a point of translucency. Some mutant hearts demonstrated pericardial fibrosis and less severe HD, with an underlying atrial or ventricular thrombus that likely caused sudden death. As seen in the inbred $\mathrm{A} / \mathrm{J}^{\mathrm{HD}}$ mutant line, affected recombinant mice from the various crosses also exhibited gross signs of HD at or near death, including subcutaneous edema, cardiomegaly, and fibrosis. Accordingly, the presence of HD was used as the trait for mapping in these studies, since it was universal in affected mice and easy to verify visually at necropsy.

\section{Whole mounts and Trichrome staining}

The hearts from siblings of the $\mathrm{A} / \mathrm{J}^{\mathrm{HD}}$ mutant line were processed for whole-mount imaging to demonstrate size and structural variability among affected and unaffected mice of the litter. Hearts from littermates were taken when the first sibling showed signs of HD (e.g., panting, inactivity, ungroomed, and weight gain from pericardial and peripheral edema). Hearts were excised, cleared in phosphate-buffered saline, photographed with a dissecting microscope at low setting, coronally cut through the 4 chambers and re-photographed at the same settings. Hearts were then placed in $10 \%$ phosphate-buffered formalin overnight and submitted to the Cincinnati Children's Research Pathology Core for standard processing, paraffin embedding and staining with Trichrome.

\section{Mapping studies}

Females from four different inbred strains were mated with proven $\mathrm{A} / \mathrm{J}^{\mathrm{HD}}$ mutant males (i.e., previously sired at least one offspring with verified HD) to generate recombinants for mapping the EM/HD trait. All inbred strains used in crosses were originally obtained from The Jackson Laboratory (JAX; Bar Harbor, ME) and maintained inhouse as small cohorts for breeding needs. If maintained in the colony, inbred strain breeders were replaced after five generations to preserve genetic background integrity with the 'Jackson' substrain. Inbred mice used for QTL mapping included: 129S1/SvImJ (S1; JAX stock \#002448); C57BL/6 J (B6; JAX stock \#000664), DBA/2 J (D2; JAX stock \#000671), and SJL/J (SJ; JAX stock \#000686). Populations for mapping the HD trait were generated using backcross $\left(\mathrm{N}_{2}\right)$ and/or intercross $\left(\mathrm{F}_{2}\right)$ breeding schemes among these four inbred strains (Additional file 7). Recombinant mice from all crosses were closely monitored and aged up to 20-weeks old to identify mice with HD, an age that accounted for $\sim 85 \%$ of all deaths in affected mice of the $\mathrm{A} / \mathrm{J}^{\mathrm{HD}}$ line. The affected populations for QTL analysis also included a few older breeders with verified HD. Unaffected recombinant mice used in QTL analysis included littermates without signs of HD (e.g., behavior and appearance; heart at necropsy) at sacrifice (at least 20weeks old).

\section{Genotyping}

To remove the $\mathrm{B} 6$ congenic region on chromosome 17 in the original founder mutant, microsatellite markers (IDT; Coralville, IA) polymorphic between A/J and B6 mice were typed, including D17Mit178 (48.71 Mb; Bld38), D17Mit139 (52.66 Mb), D17Mit88 (57.37 Mb), and D17Mit39 (74.28 $\mathrm{Mb})$. DNA isolation, PCR and gel electrophoresis were performed as described previously [61, 62]. For linkage analysis, DNA isolated from tail tips of affected and unaffected mice from the $\mathrm{A} / \mathrm{J}^{\mathrm{HD}}$ crosses were genotyped for $\sim 143,000$ SNPs using the GigaMUGA array [63] at GeneSeek (Lincoln, NE; a subsidiary of Neogen Corporation). A total of 134 DNA samples with high-quality SNP results were used in the QTL analyses.

\section{QTL and haplotype analyses}

Linkage analysis was performed using the R/qtl software package [16, 17], after checking quality and intensity normalization of the SNP data using routines provided in the R-package argyle [18]. Affected and unaffected $\mathrm{N}_{2}$ and $F_{2}$ recombinants from D2- or SJ-derived crosses were analyzed separately to identify cross-specific QTLs. For linkage analysis, the GigaMUGA SNP profile was reduced to the informative markers and the trait designated as the presence or absence of HD. Genomewide empirical thresholds were obtained within the R/qtl program. The scantwo function within R/qtl was used to assess possible interactions between the QTLs. Following QTL analysis, the whole genome (with specific focus on the linkage regions) was inspected by haplotype analysis using genotype color-coding in an Excel spreadsheet. Haplotype analysis allowed us to identify specific recombinant mice with crossovers that defined the minimal QTL interval associated with the HD trait and to predict the likely mode of inheritance of each locus.

\section{Statistical analysis}

Differences in HD rates between the sexes (2 categorical variables) were assessed for each cross using a Chi-square test and $p<0.05$ for significance. QTL significance levels for each analysis were determined using at least 1000 permutations of the respective datasets [64]. Genomewide threshold levels for linkage were set at $p<0.01$ (highly significant), $p<0.05$ (significant) and $p<0.67$ (suggestive). 


\section{Supplementary information}

Supplementary information accompanies this paper at https://doi.org/10. 1186/s12864-019-6108-0.

Additional file 1. File contains a figure that shows an overview and outcomes from 4 rounds of breeding crosses to map the EM/HD trait.

Additional file 2. File contains the QTL analysis results of D2.HD- $F_{2}$ and the combined D2.HD-N 2 and D2.HD-F $F_{2}$ cohorts.

Additional file 3. File contains the QTL analysis results of the combined SJ.HD-N 2 and SJ.HD-F 2 cohorts.

Additional file 4. File containing color-coded SNP genotypes for the haplotype analysis relevant to Fig. 5 .

Additional file 5. File contains a table for the concordance of QTL genotypes with HD in recombinant mice used in the QTL analysis.

Additional file 6. File contains a table listing the positional candidate gene elements for the three QTLS.

Additional file 7. File contains a figure summarizing the breeding schemes for mapping the HD trait.

\section{Abbreviations}

A/J: Inbred mouse strain A from Jackson Lab (J); B6: C57BL/6 J inbred mouse strain; C5: Hemolytic complement; CB3: Coxsackievirus B3; Chr: Chromosome; D2: Inbred mouse strain DBA/2 J; Dysf: Dysferlin protein (DYSF) or gene

(Dysf); EGPA: Eosinophilic granulomatosis with polyangiitis (aka Churg-Strauss Syndrome); EM: Eosinophilic myocarditis; Emhd: Quantitative trait, eosinophilic myocarditis to heart disease; HD: Heart disease; HES: Hypereosinophilic Syndrome; IBD: Identical-by-descent; JAX: Jackson Laboratory; LOD: A logarithmic score representing the likelihood of linkage, specifically the log of the odds ratio for linkage to non-linkage; Mb: Megabases; MUGA: Mouse universal genotyping array; QTL: Quantitative trait locus; SJ: Inbred mouse strain SJL/J; SNP: Single nucleotide polymorphism

\section{Acknowledgments}

We thank Ms. Hanna Osinska, Ph.D. for whole-mount imaging and coronal cuts of the control and mutant mouse hearts and the serial Trichrome imaging. We acknowledge the many dedicated laboratory staff and students over the years that managed and closely monitored the mutant mouse colony.

\section{Authors' contributions}

WJG and SMH maintained the mouse lines, managed all the crosses, genotyped and phenotyped the mice, isolated DNA, and performed studies. WJG also performed the scanone and scantwo QTL analyses and generated associated QTL plots. NZ provided expertise and advise in pathology, interpretations of histopathology slides, and helped write, edit and review the manuscript. DRP conceived of the studies and oversaw the project, analyzed the data, generated all tables and final figures, and wrote the original draft of the manuscript. All coauthors read, provided input and approved submission of the manuscript.

\section{Funding}

This project was funded by NIH grant HL135507 (DRP and NZ) and a Pilot Project from the University of Cincinnati Center for Environmental Genetics, NIEHS award P30ES006096 (DRP). These funding bodies played no role in the design of these studies, the collection, analysis, and interpretation of data, nor the writing of the manuscript.

\section{Availability of data and materials}

The datasets used and/or analyzed during the current study are available from the corresponding author on reasonable request.

\section{Ethics approval}

Mice were handled in accordance with the protocols approved by the Institutional Animal Care and Use Committee at Cincinnati Children's Hospital Medical Center; Protocol \#: IACUC 2016-0048 (DRP).

\section{Consent for publication}

Not applicable.

\section{Competing interests}

The authors declare that they have no competing interests.

\section{Author details}

${ }^{1}$ Division of Allergy and Immunology, Cincinnati Children's Hospital Medical Center, Cincinnati, OH, USA. ${ }^{2}$ Department of Pediatrics, University of Cincinnati College of Medicine, Cincinnati, OH, USA. ${ }^{3}$ Division of Human Genetics, Cincinnati Children's Hospital Medical Center, 3333 Burnet Avenue, Bldg. R. MLC 7016, Cincinnati, OH 45229-3039, USA.

Received: 10 June 2019 Accepted: 20 September 2019

Published online: 11 October 2019

\section{References}

1. Fairfield H, Srivastava A, Ananda G, Liu R, Kircher M, Lakshminarayana A, Harris BS, Karst SY, Dionne LA, Kane CC, et al. Exome sequencing reveals pathogenic mutations in 91 strains of mice with Mendelian disorders. Genome Res. 2015;25(7):948-57.

2. Prows DR, Klingler A, Gibbons WJ Jr, Homan SM, Zimmermann N. Characterization of a mouse model of hypereosinophilia-associated heart disease. Am J Physiol Heart Circ Physiol. 2019;317(2):H405-14.

3. Gervais F, Desforges C, Skamene E. The C5-sufficient a/J congenic mouse strain. Inflammatory response and resistance to listeria monocytogenes. J Immunol. 1989;142(6):2057-60.

4. Jagannath C, Hoffmann H, Sepulveda E, Actor JK, Wetsel RA, Hunter RL. Hypersusceptibility of a/J mice to tuberculosis is in part due to a deficiency of the fifth complement component (C5). Scand J Immunol. 2000;52(4):369-79.

5. Mullick A, Leon Z, Min-Oo G, Berghout J, Lo R, Daniels E, Gros P. Cardiac failure in C5-deficient a/J mice after Candida albicans infection. Infect Immun. 2006;74(8):4439-51.

6. Tuite A, Elias M, Picard S, Mullick A, Gros P. Genetic control of susceptibility to Candida albicans in susceptible $\mathrm{a} / \mathrm{J}$ and resistant $\mathrm{C} 57 \mathrm{BL} / 6 \mathrm{~J}$ mice. Genes Immun. 2005;6(8):672-82.

7. Baumann U, Chouchakova N, Gewecke B, Kohl J, Carroll MC, Schmidt RE, Gessner JE. Distinct tissue site-specific requirements of mast cells and complement components C3/C5a receptor in IgG immune complexinduced injury of skin and lung. J Immunol. 2001;167(2):1022-7.

8. Hawlisch $\mathrm{H}$, Kohl J. Complement and toll-like receptors: key regulators of adaptive immune responses. Mol Immunol. 2006;43(1-2):13-21.

9. Heller T, Gessner JE, Schmidt RE, Klos A, Bautsch W, Kohl J. Cutting edge: fc receptor type I for lgG on macrophages and complement mediate the inflammatory response in immune complex peritonitis. J Immunol. 1999; 162(10):5657-61.

10. Morgan BP, Harris CL. Complement, a target for therapy in inflammatory and degenerative diseases. Nat Rev Drug Discov. 2015;14(12):857-77.

11. Pandey MK, Grabowski GA. Immunological cells and functions in Gaucher disease. Crit Rev Oncog. 2013;18(3):197-220.

12. Wetsel RA, Fleischer DT, Haviland DL. Deficiency of the murine fifth complement component (C5). A 2-base pair gene deletion in a 5'-exon. J Biol Chem. 1990;265(5):2435-40.

13. Ho M, Post CM, Donahue LR, Lidov HG, Bronson RT, Goolsby H, Watkins SC, Cox GA, Brown RH Jr. Disruption of muscle membrane and phenotype divergence in two novel mouse models of dysferlin deficiency. Hum Mol Genet. 2004:13(18):1999-2010.

14. Bittner RE, Anderson LV, Burkhardt E, Bashir R, Vafiadaki E, Ivanova S, Raffelsberger T, Maerk I, Hoger H, Jung M, et al. Dysferlin deletion in SJL mice (SJL-Dysf) defines a natural model for limb girdle muscular dystrophy 2B. Nat Genet. 1999:23(2):141-2.

15. Kobayashi K, Izawa T, Kuwamura M, Yamate J. Dysferlin and animal models for dysferlinopathy. J Toxicol Pathol. 2012;25(2):135-47.

16. Broman KW, Sen S. A guide to QTL mapping with R/qtl. New York: Springer; 2009.

17. Broman KW, Wu H, Sen S, Churchill GA. R/qtl: QTL mapping in experimental crosses. Bioinformatics. 2003;19(7):889-90.

18. Morgan AP. argyle: An R package for analysis of Illumina genotyping arrays. G3 (Bethesda). 2015;6(2):281-6.

19. Kuijpers TW, Tool ATJ, van der Bijl I, de Boer M, van Houdt M, de Cuyper IM, Roos D, van Alphen F, van Leeuwen K, Cambridge EL, et al. Combined immunodeficiency with severe inflammation and allergy caused by ARPC1B deficiency. J Allergy Clin Immunol. 2017;140(1):273-7 e210. 
20. Hall DD, Ponce JM, Chen B, Spitler KM, Alexia A, Oudit GY, Song LS, Grueter CE. Ectopic expression of Cdk8 induces eccentric hypertrophy and heart failure. JC Insight. 2017;2(15):e92476. https:/doi.org/10.1172/jci.insight.92476.

21. Mei L, Huang Y, Lin J, Chu M, Hu C, Zhou N, Wu L. Increased cardiac remodeling in cardiac-specific Flt-1 receptor knockout mice with pressure overload. Cell Tissue Res. 2015;362(2):389-98.

22. Pfister O, Lorenz V, Oikonomopoulos A, Xu L, Hauselmann SP, Mbah C, Kaufmann BA, Liao R, Wodnar-Filipowicz A, Kuster GM. FLT3 activation improves post-myocardial infarction remodeling involving a cytoprotective effect on cardiomyocytes. J Am Coll Cardiol. 2014;63(10):1011-9.

23. D'Agostino M, Tornillo G, Caporaso MG, Barone MV, Ghigo E, Bonatti S, Mottola G. Ligand of numb proteins LNX1p80 and LNX2 interact with the human glycoprotein CD8alpha and promote its ubiquitylation and endocytosis. J Cell Sci. 2011;124(Pt 21):3545-56.

24. Norum HM, Gullestad L, Abraityte A, Broch K, Aakhus S, Aukrust P, Ueland T. Increased serum levels of the notch ligand DLL1 are associated with diastolic dysfunction, reduced exercise capacity, and adverse outcome in chronic heart failure. J Card Fail. 2016;22(3):218-23.

25. Apostolidis SA, Rodriguez-Rodriguez N, Suarez-Fueyo A, Dioufa N, Ozcan E, Crispin JC, Tsokos MG, Tsokos GC. Phosphatase PP2A is requisite for the function of regulatory T cells. Nat Immunol. 2016;17(5):556-64.

26. Jain M, Jakubowski A, Cui L, Shi J, Su L, Bauer M, Guan J, Lim CC, Naito Y, Thompson JS, et al. A novel role for tumor necrosis factor-like weak inducer of apoptosis (TWEAK) in the development of cardiac dysfunction and failure. Circulation. 2009;119(15):2058-68.

27. Shahini N, Michelsen AE, Nilsson PH, Ekholt K, Gullestad L, Broch K, Dahl CP, Aukrust $P$, Ueland T, Mollnes TE, et al. The alternative complement pathway is dysregulated in patients with chronic heart failure. Sci Rep. 2017;7:42532.

28. Selli ME, Thomas AC, Wraith DC, Newby AC. A humanized HLA-DR4 mouse model for autoimmune myocarditis. J Mol Cell Cardiol. 2017;107:22-6.

29. Kubota T, McTiernan CF, Frye CS, Demetris AJ, Feldman AM. Cardiac-specific overexpression of tumor necrosis factor-alpha causes lethal myocarditis in transgenic mice. J Card Fail. 1997;3(2):117-24.

30. Benschop R, Wei T, Na S. Tumor necrosis factor receptor superfamily member 21: TNFR-related death receptor-6, DR6. Adv Exp Med Biol. 2009;647:186-94.

31. Ogbogu PU, Rosing DR, Horne MK 3rd. Cardiovascular manifestations of hypereosinophilic syndromes. Immunol Allergy Clin N Am. 2007;27(3):457-75.

32. Groh M, Pagnoux C, Baldini C, Bel E, Bottero P, Cottin V, Dalhoff K, Dunogue B, Gross W, Holle J, et al. Eosinophilic granulomatosis with polyangiitis (Churg-Strauss) (EGPA) consensus task force recommendations for evaluation and management. Eur J Intern Med. 2015;26(7):545-53.

33. Bashir R, Britton S, Strachan T, Keers S, Vafiadaki E, Lako M, Richard I, Marchand S, Bourg N, Argov Z, et al. A gene related to Caenorhabditis elegans spermatogenesis factor fer- 1 is mutated in limb-girdle muscular dystrophy type 2B. Nat Genet. 1998;20(1):37-42.

34. Liu J, Aoki M, Illa I, Wu C, Fardeau M, Angelini C, Serrano C, Urtizberea JA, Hentati F, Hamida MB, et al. Dysferlin, a novel skeletal muscle gene, is mutated in Miyoshi myopathy and limb girdle muscular dystrophy. Nat Genet. 1998;20(1):31-6

35. Bansal D, Miyake K, Vogel SS, Groh S, Chen CC, Williamson R, McNeil PL, Campbell KP. Defective membrane repair in dysferlin-deficient muscular dystrophy. Nature. 2003;423(6936):168-72.

36. Chase TH, Cox GA, Burzenski L, Foreman O, Shultz LD. Dysferlin deficiency and the development of cardiomyopathy in a mouse model of limb-girdle muscular dystrophy 2B. Am J Pathol. 2009;175(6):2299-308.

37. Han R, Bansal D, Miyake K, Muniz VP, Weiss RM, McNeil PL, Campbell KP. Dysferlin-mediated membrane repair protects the heart from stress-induced left ventricular injury. J Clin Invest. 2007;117(7):1805-13.

38. Lammerding J, Lee RT. Torn apart: membrane rupture in muscular dystrophies and associated cardiomyopathies. J Clin Invest. 2007;117(7):1749-52.

39. Gangaplara A, Massilamany C, Brown DM, Delhon G, Pattnaik AK, Chapman $\mathrm{N}$, Rose N, Steffen D, Reddy J. Coxsackievirus B3 infection leads to the generation of cardiac myosin heavy chain-alpha-reactive CD4 T cells in a/J mice. Clin Immunol. 2012;144(3):237-49.

40. Radovanovic I, Mullick A, Gros P. Genetic control of susceptibility to infection with Candida albicans in mice. PLoS One. 2011;6(4):e18957.

41. Leon JS, Godsel LM, Wang K, Engman DM. Cardiac myosin autoimmunity in acute Chagas' heart disease. Infect Immun. 2001;69(9):5643-9.

42. Wang C, Wong J, Fung G, Shi J, Deng H, Zhang J, Bernatchez P, Luo H. Dysferlin deficiency confers increased susceptibility to coxsackievirusinduced cardiomyopathy. Cell Microbiol. 2015;17(10):1423-30.
43. Hirasawa M, Kitaura Y, Deguchi H, Ukimura A, Kawamura K. Spontaneous myocarditis in DBA/2 mice. Light microscopic study with transmission and $X$ ray analytical electron microscopic studies. Virchows Arch. 1998;432(5):461-8.

44. Metcalf D, Alexander WS, Ryan PJ, Mifsud S, Di Rago L. Production of colony-stimulating factors and IL-5 by organs from three types of mice with inflammatory disease due to loss of the suppressor of cytokine signaling-1. J Immunol. 2001;167(8):4661-7.

45. Yoshida T, Fukuda T, Hatano M, Koseki H, Okabe S, Ishibashi K, Kojima S, Arima M, Komuro I, Ishii G, et al. The role of Bcl6 in mature cardiac myocytes. Cardiovasc Res. 1999;42(3):670-9.

46. Barin JG, Baldeviano GC, Talor MV, Wu L, Ong S, Fairweather D, Bedja D, Stickel NR, Fontes JA, Cardamone AB, et al. Fatal eosinophilic myocarditis develops in the absence of IFN-gamma and IL-17A. J Immunol. 2013;191(8): 4038-47.

47. Jane-wit D, Yu M, Edling AE, Kataoka S, Johnson JM, Stull LB, Moravec CS, Tuohy VK. A novel class II-binding motif selects peptides that mediate organ-specific autoimmune disease in SWXJ, SJL/J, and SWR/J mice. J Immunol. 2002;169(11):6507-14.

48. Rabin ER, Hassan SA, Jenson AB, Melnick JL. Coxsackie virus B3 myocarditis in mice. An Electron microscopic, immunofluorescent and virus-assay study. Am J Pathol. 1964:44:775-97.

49. Hirasawa M, Deguchi H, Ukimura A, Kitaura Y. Immunologic interaction between infiltrating eosinophils and T lymphocytes in murine spontaneous eosinophilic myocarditis. Int Arch Allergy Immunol. 2003;130(1):73-81.

50. Elliott JF, Liu J, Yuan ZN, Bautista-Lopez N, Wallbank SL, Suzuki K, Rayner D, Nation P, Robertson MA, Liu G, et al. Autoimmune cardiomyopathy and heart block develop spontaneously in HLA-DQ8 transgenic IAbeta knockout NOD mice. Proc Natl Acad Sci U S A. 2003;100(23):13447-52.

51. Liu J, Purdy LE, Rabinovitch S, Jevnikar AM, Elliott JF. Major DQ8-restricted Tcell epitopes for human GAD65 mapped using human CD4, DQA1*0301, DQB1*0302 transgenic IA (null) NOD mice. Diabetes. 1999;48(3):469-77.

52. Taneja V, David CS. Spontaneous autoimmune myocarditis and cardiomyopathy in HLA-DQ8.NODAbo transgenic mice. J Autoimmun. 2009; 33(3-4):260-9.

53. Poffenberger MC, Shanina I, Aw C, El Wharry N, Straka N, Fang D, Baskin-Hill AE, Spiezio SH, Nadeau JH, Horwitz MS. Novel nonmajor histocompatibility complex-linked loci from mouse chromosome 17 confer susceptibility to viral-mediated chronic autoimmune myocarditis. Circ Cardiovasc Genet. 2010;3(5):399-408.

54. Nadeau JH, Singer JB, Matin A, Lander ES. Analysing complex genetic traits with chromosome substitution strains. Nat Genet. 2000;24(3):221-5.

55. Herskowitz A, Beisel KW, Wolfgram LJ, Rose NR. Coxsackievirus B3 murine myocarditis: wide pathologic spectrum in genetically defined inbred strains. Hum Pathol. 1985;16(7):671-3.

56. Lin AY, Nutman TB, Kaslow D, Mulvihill JJ, Fontaine L, White BJ, Knutsen T, Theil KS, Raghuprasad PK, Goldstein AM, et al. Familial eosinophilia: clinical and laboratory results on a U.S. kindred. Am J Med Genet. 1998;76(3):229-37.

57. Vaglio A, Buzio C, Zwerina J. Eosinophilic granulomatosis with polyangiitis (Churg-Strauss): state of the art. Allergy. 2013;68(3):261-73.

58. Raby BA. Asthma severity, nature or nurture: genetic determinants. Curr Opin Pediatr. 2019;31(3):340-8.

59. Jawairia M, Shahzad G, Mustacchia P. Eosinophilic gastrointestinal diseases: review and update. ISRN Gastroenterol. 2012;2012:463689.

60. Harley JB, Fauci AS, Gralnick HR. Noncardiovascular findings associated with heart disease in the idiopathic hypereosinophilic syndrome. Am J Cardiol. 1983;52(3):321-4.

61. Prows DR, Gibbons WJ Jr, Smith JJ, Pilipenko V, Martin LJ. Age and sex of mice markedly affect survival times associated with hyperoxic acute lung injury. PLoS One. 2015;10(6):e0130936.

62. Prows DR, Hafertepen AP, Winterberg AV, Gibbons WJ Jr, Liu C, Nick TG. Genetic analysis of hyperoxic acute lung injury survival in reciprocal intercross mice. Physiol Genomics. 2007;30(3):271-81.

63. Morgan AP, Fu CP, Kao CY, Welsh CE, Didion JP, Yadgary L, Hyacinth L, Ferris MT, Bell TA, Miller DR, et al. The Mouse universal genotyping array: From substrains to subspecies. G3 (Bethesda). 2015;6(2):263-79.

64. Doerge RW, Churchill GA. Permutation tests for multiple loci affecting a quantitative character. Genetics. 1996;142(1):285-94.

\section{Publisher's Note}

Springer Nature remains neutral with regard to jurisdictional claims in published maps and institutional affiliations. 